\title{
Fluoride Induces Morphological and Biochemical Changes in Goat Eye Lens
}

\author{
Sudhanshu Mishra ${ }^{1,2}$, Swati Tomar ${ }^{2,3}$, Anant Sharma ${ }^{1,2}$, Dushyant Singh Chauhan ${ }^{1,4}$ and Sandeep Tripathi $^{1 *}$ \\ ${ }^{1}$ National Referral Centre for Fluoride poisoning in India, Nims University, Jaipur, India \\ ${ }^{2}$ Department of Advanced Sciences \& Biotechnology, Nims Institute of Engineering \& Technology, Nims University, Jaipur, India \\ ${ }^{3}$ Department of Ophthalmology, Nims Medical College, Nims University, Jaipur, India \\ ${ }^{4}$ Departments of Paediatrics, Nims Medical College \& Hospital, Nims University, Jaipur, India
}

\begin{abstract}
In the present study, we attempted to find out the biochemical changes in goat eye lens due to Fluoride. Twenty four goat eye lenses were divided into four groups $(\mathrm{N}=6)$. Three experimental groups were incubated with three different concentration of Fluoride $(50,100$ and 200 ppm) for 24 hours at room temperature. After incubation, lens were homogenised to estimate Lipid peroxide level (LPO), Protein carbonyl content (PC), total protein (TP), GSH and antioxidant enzymes such as SOD and CAT. We observed that gradually, LPO and PC were significantly ( $p<0.001)$ increased with the fluoride concentration while reduced glutathione level (GSH) and antioxidant enzymes, superoxide dismutase (SOD) and catalase (CAT) were significantly decreased with the increased concentration of fluoride. On the basis of the results, It may conclude that uptake of excess consumption of Fluoride may be linked with increased oxidative burden which may lead to lens opacification, progression and sometimes leads to development of cataract.
\end{abstract}

\section{Keywords: Fluoride; Lens; Oxidative stress}

\section{Introduction}

Endemic fluoride is a major problem for crippling, skeletal and dental disease caused by the ingestion of large amount of fluoride from drinking water of endemic areas. Although systemic causes of fluorosis have extensive variety of disorders of fluorosis have a wide variety of manifestations. The wide spread distribution of fluoride in nature is a direct source of adverse health effects in human populations. Fluoride exposure exhibits rapid increased transport in blood stream and likely across the blood-brain barrier. In addition of the knowledge, very little attention has been known to the spectrum of lenticular findings. High concentration of fluoride in the drinking water is one of the major sources of generation of free radicals in lens. Free radicals are highly reactive, unstable molecules that react rapidly with adjacent molecules via a variety of reactions including: hydrogen abstraction (capturing), electron donation and electron sharing [1]. The process of capturing an electron involves reacting with a donor molecule, which loses an electron and is said to have been oxidized [2]. Endogenous antioxidant like reduced glutathione is present in high concentration in lens; Superoxide dismutase and catalase keep the level of free radicals below toxic levels [3].

The aim of the study was to assess the effect of fluoride on the goat eye lens by estimation of the status of total antioxidant (TA) level, and activities of the enzymes reduced glutathione (GSH) and superoxide dismutase (SOD), as a marker of oxidative stress.

\section{Methods}

\section{Group and treatment}

A total of 24 lenses were used for the study. Goat lenses were divided into four groups and each group contain six lenses. The lenses were incubated in artificial aqueous humour with different concentration of sodium fluoride (50, 100 and $200 \mathrm{ppm}$ ) for 24 hours. The groups are defined as Group I: Control; Group II: Fluoride 50 ppm; Group III: Fluoride 100 ppm and Group IV: Fluoride 200 ppm. The doses were selected on the based on our previous experiments. Minimum effective dose were The Institutional Animal Ethics Committee approved the study prior to the initiation of the experiment and also approved all experimental protocols.

\section{Lens culture}

The study was carried out on goat eye lens obtained from local slaughter house and immediately transported to the laboratory at $-4^{\circ} \mathrm{C}$ The lenses were removed by extra capsular extraction and incubated in artificial aqueous humour $\left(\mathrm{NaCl} 140 \mathrm{mM}, \mathrm{KCl} 5 \mathrm{mM}, \mathrm{MgCl}_{2} 2 \mathrm{mM}\right.$, $\mathrm{NaHCO}_{3} 0.5 \mathrm{mM}, \mathrm{NaH}(\mathrm{PO} 4)_{2} 0.5 \mathrm{mM}, \mathrm{CaCl}_{2} 0.4 \mathrm{mM}$ and glucose 5.5 $\mathrm{mM})$ at room temperature and $\mathrm{pH} 7.8$ for $72 \mathrm{hrs}$. Penicillin $(32 \mathrm{mg})$ and streptomycin $(250 \mathrm{mg})$ were added to the culture media to prevent bacterial contamination [4].

\section{Biochemical analysis}

Tissue homogenate preparation: After 24 hours of the incubation period, lenses were processed for biochemical analysis. Ten percent $(\mathrm{w} / \mathrm{v})$ homogenate of the lenses were prepared by of York's homogenizer fitted with Teflon plunger in $0.1 \mathrm{M}$ phosphate buffer $(\mathrm{pH}$ 7.1). The whole homogenate was centrifuged at $4000 \mathrm{x} g$ for 10 minutes in a refrigerated centrifuge. The resultant supernatant was used for biochemical parameters.

Protein and protein carbonyl content: The protein content was measured [5] using bovine serum albumin (BSA) as standard. It was represented as $\mathrm{mg} / \mathrm{g}$ protein. Protein carbonyl content was determined in the samples by measuring the DNPH adducts at $375 \mathrm{~nm}$. Carbonyl

*Corresponding author: Dr. Sandeep Tripathi, Assistant Professor of Biotechnology, Head (R \& D) National Referral Centre for Fluoride Poisoning in India, Nims University, Shobha Nagar, Jaipur-303121 India, Tel: +918955577013; E-mail: sandeeptripathiphd@gmail.com

Received May 20, 2014; Accepted June 30, 2014; Published July 03, 2014

Citation: Mishra S, Tomar S, Sharma A, Chauhan DS, Tripathi S (2014) Fluoride Induces Morphological and Biochemical Changes in Goat Eye Lens. J Environ Anal Toxicol 4: 231. doi: 10.4172/2161-0525.1000231

Copyright: @ 2014 Mishra S, et al. This is an open-access article distributed under the terms of the Creative Commons Attribution License, which permits unrestricted use, distribution, and reproduction in any medium, provided the original author and source are credited. 
contents were calculated by using a molar extinction coefficient (e) of $22,000 \mathrm{M}^{-1} \mathrm{~cm}^{-1}$. Data were expressed as nmoles carbonyl $/ \mathrm{mg}$.

Lipid peroxide levels (LPO): The lipid peroxide (LPx) levels were measured by the method of Okhawa et al. [6]. The thiobarbituric acid reacting substances (TBARS) of the sample were estimated spectrophotometrically at $532 \mathrm{~nm}$. The rate of lipid peroxidation was expressed as $\mathrm{n}$ mole of $\mathrm{MDA} / \mathrm{g}$ tissue.

\section{Measurement of endogenous enzymes}

The lens homogenates were used for the assay of enzymatic antioxidants. The superoxide dismutase (SOD EC 1:15.1.1) activity was determined from its ability to inhibit the reduction of NBT in presence of PMS [7]. The reaction was monitored spectrophotometrically at $560 \mathrm{~nm}$. The SOD activity was expressed as U/mg protein (1 unit is the amount of enzyme that inhibit the reduction of NBT by one half in above reaction mixture). Catalase (CAT, EC 1.11.1.6) activity was assayed using hydrogen peroxide as substrate; the decomposition of $\mathrm{H}_{2} \mathrm{O}_{2}$ was followed at $240 \mathrm{~nm}$ on spectrophotometer. The CAT activity was expressed as $\mathrm{U} / \mathrm{mg}$ protein [8]. The reduced glutathione (GSH) was estimation by the use of Ellman reagent (5,5' dithiobis (2-nitro benzoic acid). The optical density of the pale colour was measured on the spectrophotometer on $412 \mathrm{~nm}$. An appropriate standard (pure GSH) was run simultaneously. The level of GSH was expressed as $\mu \mathrm{g} / \mathrm{g}$ tissue [9].

\section{Statistical analysis}

Experimental data were summarized as Mean $\pm S D(n=6)$. Groups were compared together by one way analysis of variance followed by Student Newman-Keuls post hoc test. The acceptance level of significance was $\mathrm{p}<0.05$. InStat (version 3 ) was used for analysis of data.

\section{Results and Discussion}

In the present study we observed significant opacification in the goat eye lenses after $24 \mathrm{hrs}$ incubation with sodium fluoride (Figure 1). The maximum opacification was observed gradually with the increasing amount of the fluoride. Several studies reveal that oxidative stress and radical oxygen species are responsible for lens opacification and cataract development [10]. Free radicals are capable of perturbing the homeostasis of lens leading to loss of transparency. The concentration of protein was found to be reduced in fluoride treated rats when compared with the untreated controls (Figure 2). This finding has supported by the increased protein carbonization (PC) in treated rats. These changes were gradually increased with the concentration of fluoride. The lenses are composed of transparent crystalline protein. The oxidation of lens proteins by free radicals and reactive oxygen species play an important role in the process leading to lens opacification [11]. Free radical-induced lipid peroxidation in the goat eyes is a very destructive progression of cataract and it may be due to fluoride induced free radical generation. Previously it has been reported that the accumulated peroxidation products damage vital membrane structures [12]. In the present study, such a disturbance was noted in membrane lipids as a result of increased production of MDA. As evident in our study increased rate of lipid peroxidation was observed in fluoride treated goat eyes when compared with the untreated lenses. The antioxidant profiles i.e, SOD, CAT and GSH were also evaluated in the goat eye lenses (Figure 3). The activity of SOD and CAT were found to be significantly in fluoride treated goat eyes. The maximum reduction was observed in the group- 4 and minimum in group-2. While the GSH content was also reduced in similar pattern.
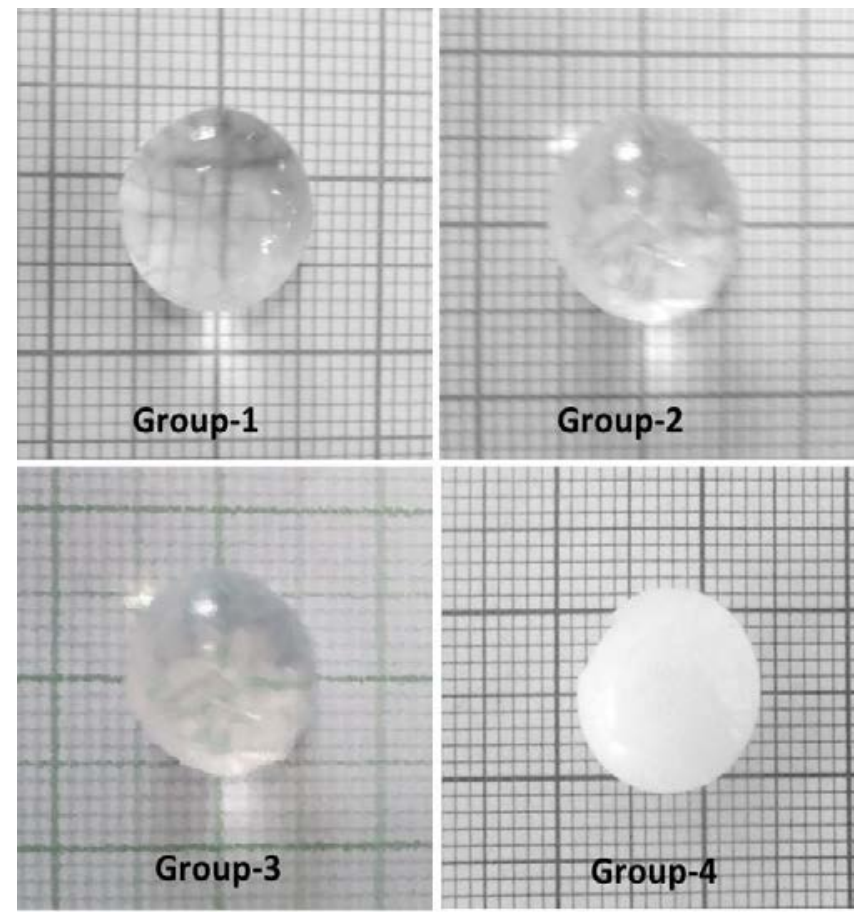

Figure 1: Fluoride induced opecification of goat eye lens (A) control, (B) $50 \mathrm{ppm}$ fluoride treated, (C) $100 \mathrm{ppm}$ fluoride treated and (C) $200 \mathrm{ppm}$ fluoride treated lens.

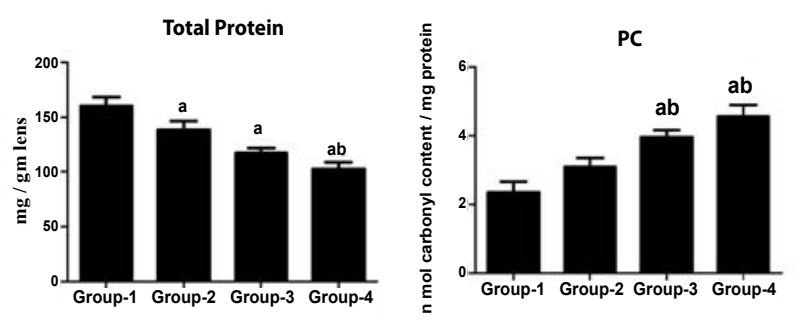

LPO

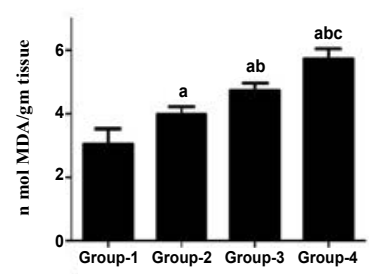

Figure 2: Levels of Total Protein (TP), protein carbonyl content (PC) and lipid peroxide levels (LPO) in control and fluoride treated groups. The results are expressed as Mean \pm SD in six rat of each group. Superscripts relate significant $(p<0.05)$ comparison with Group-1(a), Group-2(b), Group-3(c), Group-4(d).

The mode of action of fluoride induced cataractogenesis has not been completely defined, but this study reported that the main biochemical actions is oxidative burden by increased rate of reactive oxygen species in the aqueous humor in combination with a decrease in the activity of antioxidant enzymes such as SOD, CAT and GSH. Our results are concomitant with previous study [13]. Catalase is an important part of 
Citation: Mishra S, Tomar S, Sharma A, Chauhan DS, Tripathi S (2014) Fluoride Induces Morphological and Biochemical Changes in Goat Eye Lens. J Environ Anal Toxicol 4: 231. doi: 10.4172/2161-0525.1000231

Page 3 of 3

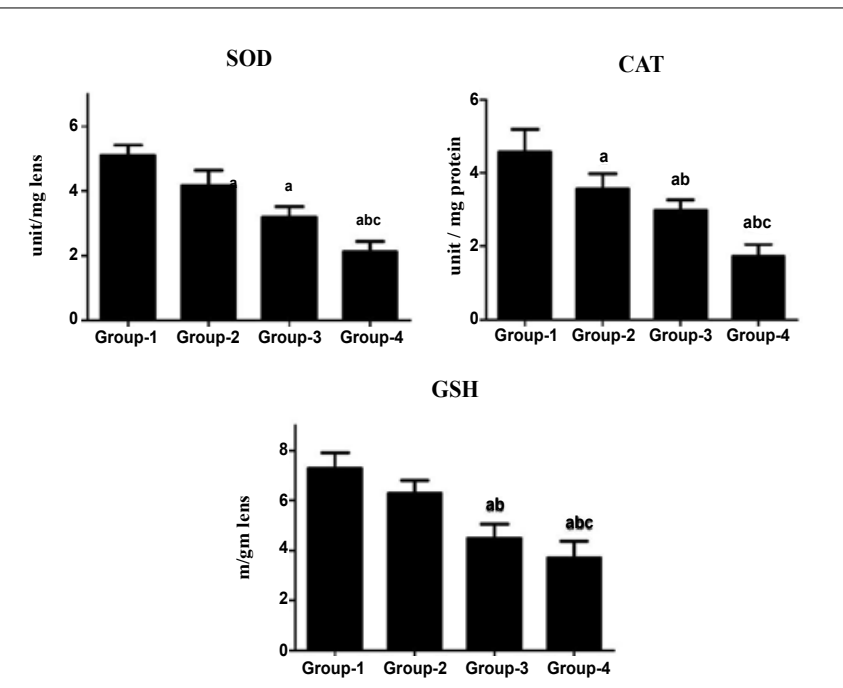

Figure 3: Activity of Superoxide dismutase (SOD), Catalase (CAT) and reduced, reduced content (GSH) in control and fluoride treated groups. The results are expressed as Mean $\pm \mathrm{SD}$ in six rat of each group. Superscripts relate significant $(p<0.05)$ comparison with Group-1(a), Group-2(b), Group3(c), Group-4(d)

the innate enzymatic defense system of the lens which is responsible for the detoxification of $\mathrm{H}_{2} \mathrm{O}_{2}$. Decrease in the activities of these enzymes in tissues has been linked with the build-up of highly reactive free radicals leading to injurious effects such as loss of integrity and function of cell membranes [14]. In this study, the level of catalase was found to be less in toxic control lens as compared to normal control group. The amount of reduced glutathione in the lens decreases in almost in any type of cataract [15]. The role of reduced glutathione in the preservation of lens clarity is of substantial interest; it serves as the major antioxidant in the lens and prevents protein oxidation [16]. It is suggested that under stressful circumstance, causing protein aggregation, precipitation leading to lens opalescence due to protein denaturation of the lens [17].

\section{Conclusion}

On the basis of results it may conclude that fluoride is a potential cataractogenic agent. Thus, high endemic area may be at a risk for cataract. We put forward that ophthalmologic examinations must be conducted in fluoride sensitive areas of the country.

\section{Authors Contribution}

SM was the main investigator, performed experiment and collected data. AS was conducted microscopic observations for identification of opecification of the lens. DSC performed statistical analysis and presented graph. DSC was conducted animal handling and tissue processing. MC was helped in manuscript preparations. STM was evaluated lens morphology and cellular structure for the study. ST was proposed over all study design and drafted manuscript. AT was facilitated experimental design and provided well equipped lab facilities.

\section{Acknowledgement}

Author wish to thank Prof. K.C. Singhal, Vice Chancellor of the NIMS University, Jaipur India for their ideas about the study.

\section{References}

1. McCord JM (2000) The evolution of free radicals and oxidative stress. Am J Med 108: 652-659.

2. Halliwell B, Chirico S (1993) Lipid peroxidation: its mechanism, measurement and significance. Am J Clin Nutr 57: 715S-724S.

3. Halliwell B (1999) Establishing the significance and optimal intake of dietary antioxidants: the biomarker concept. Nutr Rev 57: 104-113.

4. Chandorkar AG, Albal MV, Bulakh PM, Muley MP (1981) Lens organ culture (Methodology and preliminary observations on viability and maintenance of transparency). Indian J Ophthalmol 29: 151-152.

5. Lowry OH, Rosebrough NJ, Farr AL, Randall RJ (1951) Protein measurement with the Folin phenol reagent. J Biol Chem 193: 265-275.

6. Ohkawa H, Ohishi N, Yagi K (1979) Assay for lipid peroxides in animal tissue by thiobarbituric acid reaction. Anal Biochem 95: 351-358.

7. McCord JM, Fridovich I (1969) Superoxide dismutase. An enzymic function for erythrocuprein (hemocuprein). J Biol Chem 244: 6049-6055.

8. Aebi H (1974) Catalase In: Bergmeyer HU (ed). Methods of Enzymatic Analysis 2: New York: Academic Press Inc 673-684.

9. Ellman GL (1959) Tissue sulfhydryl groups. Arch Biochem Biophysics 82: 70 77.

10. Spector A (1995) Oxidative stress-induced cataract: mechanism of action. FASEB J 9: 1173-1182.

11. Zhao W, Devamanoharan PS, Varma SD (1998) Fructose induced deactivation of glucose-6-phosphate dehydrogenase activity and its prevention by pyruvate: implications in cataract prevention. Free Radic Res 29: 315-320.

12. Awasthi S, Srivatava SK, Piper JT, Singhal SS, Chaubey M, et al. (1996) Curcumin protects against 4-hydroxy-2-trans-nonenal-induced cataract formation in rat lenses. Am J Clin Nutr 64: 761-766.

13. Shearer TR, Ma H, Fukiage C, Azuma M (1997) Selenite nuclear cataract: review of the model. Mol Vis 3: 8 .

14. Cheng L, Kellogg EW 3rd, Packer L (1981) Photoinactivation of catalase Photochem Photobiol 34: 125-129.

15. Kyselova Z, Stefek M, Bauer V (2004) Pharmacological prevention of diabetic cataract. J Diabetes Complications 18: 129-140.

16. Xie PY, Kanai A, Nakajima A, Kitahara S, Ohtsu A et al. (1991) Glutathione and glutathione-related enzymes in human cataractous lenses. Ophthalmic Res 23: 133-140.

17. Kumar MS, Koteiche HA, Claxton DP, Mchaourab HS (2009) Disulfide crosslinks in the interaction of a cataract-linked alphaA-crystallin mutant with betaB1crystallin. FEBS Lett 583: 175-179. 